\title{
Modeled cost-effectiveness of transforaminal lumbar interbody fusion compared with posterolateral fusion for spondylolisthesis using $\mathbf{N}^{2}$ QOD data
}

\author{
Leah Y. Carreon, MD, ${ }^{1}$ Steven D. Glassman, MD, ${ }^{1}$ Zoher Ghogawala, MD, ${ }^{2}$ \\ Praveen V. Mummaneni, MD, ${ }^{3}$ Matthew J. McGirt, MD, ${ }^{4}$ and Anthony L. Asher, MD ${ }^{4}$ \\ ${ }^{1}$ Norton Leatherman Spine Center, Louisville, Kentucky; ${ }^{2}$ Alan and Jacqueline Stuart Spine Center, Department of Neurosurgery, \\ Lahey Hospital and Medical Center, Burlington, Massachusetts; ${ }^{3}$ Department of Neurological Surgery, University of California, \\ San Francisco, California; and ${ }^{4}$ Carolina Neurosurgery \& Spine Associates, Charlotte, North Carolina
}

OBJECTIVE Transforaminal lumbar interbody fusion (TLIF) has become the most commonly used fusion technique for lumbar degenerative disorders. This suggests an expectation of better clinical outcomes with this technique, but this has not been validated consistently. How surgical variables and choice of health utility measures drive the cost-effectiveness of TLIF relative to posterolateral fusion (PSF) has not been established. The authors used health utility values derived from Short Form-6D (SF-6D) and EQ-5D and different cost-effectiveness thresholds to evaluate the relative cost-effectiveness of TLIF compared with PSF.

METHODS From the National Neurosurgery Quality and Outcomes Database (N²QD), 101 patients with spondylolisthesis who underwent PSF were propensity matched to patients who underwent TLIF. Health-related quality of life measures and perioperative parameters were compared. Because health utility values derived from the SF-6D and EQ-5D questionnaires have been shown to vary in patients with low-back pain, quality-adjusted life years (QALYs) were derived from both measures. On the basis of these matched cases, a sensitivity analysis for the relative cost per QALY of TLIF versus PSF was performed in a series of cost-assumption models.

RESULTS Operative time, blood loss, hospital stay, and 30-day and 90-day readmission rates were similar for the TLIF and PSF groups. Both TLIF and PSF significantly improved back and leg pain, Oswestry Disability Index (ODI) scores, and EQ-5D and SF-6D scores at 3 and 12 months postoperatively. At 12 months postoperatively, patients who had undergone TLIF had greater improvements in mean ODI scores (30.4 vs 21.1, $p=0.001)$ and mean SF-6D scores (0.16 vs $0.11, p=0.001)$ but similar improvements in mean EQ-5D scores $(0.25$ vs $0.22, p=0.415)$ as patients treated with PSF. At a cost per QALY threshold of $\$ 100,000$ and using SF-6D-based QALYS, the authors found that TLIF would be costprohibitive compared with PSF at a surgical cost of $\$ 4830$ above that of PSF. However, with EQ-5D-based QALYS, TLIF would become cost-prohibitive at an increased surgical cost of $\$ 2960$ relative to that of PSF. With the 2014 US per capita gross domestic product of $\$ 53,042$ as a more stringent cost-effectiveness threshold, TLIF would become cost-prohibitive at surgical costs $\$ 2562$ above that of PSF with SF-6D-based QALYs or at a surgical cost exceeding that of PSF by $\$ 1570$ with EQ-5D-derived QALYs.

CONCLUSIONS As with all cost-effectiveness studies, cost per QALY depended on the measure of health utility selected, durability of the intervention, readmission rates, and the accuracy of the cost assumptions.

http://thejns.org/doi/abs/10.3171/2015.10.SPINE15917

KEY WORDS transforaminal lumbar interbody fusion; posterolateral fusion; SF-6D; EQ-5D; cost-effectiveness; spinal disorders

ABBREVIATIONS N2QOD = National Neurosurgery Quality and Outcomes Database; ODI = Oswestry Disability Index; PSF = posterolateral fusion; QALY = quality-adjusted life year; TLIF = transforaminal lumbar interbody fusion.

SUBMITTED August 3, 2015. ACCEPTED October 27, 2015.

INCLUDE WHEN CITING Published online February 19, 2016; DOI: 10.3171/2015.10.SPINE15917. 
$\mathrm{T}$ HE primary goal of lumbar fusion surgery is to improve a patient's quality of life by adequately decompressing the neural structures and achieving a stable arthrodesis. However, the optimal surgical approach to treating degenerative conditions of the lumbar spine remains controversial. Although historically posterolateral spinal fusion (PSF) was the most commonly used procedure, transforaminal lumbar interbody fusion (TLIF) is increasingly becoming more common ${ }^{29}$ Theoretical advantages of TLIF over PSF include anterior column support, indirect foraminal decompression, removal of the disc as a pain generator, and restoration of lumbar lordosis. . $^{3,10,18,30,36}$ These theoretical advantages, which come at an increased cost, have not consistently translated into better clinical outcomes. . $^{12,19-21,40}$ A recent study conducting a cost-utility analysis of data from a prospective randomized trial ${ }^{20}$ reported that TLIF was not a relevant alternative to PSF from a socioeconomic, societal perspective. ${ }^{8}$

Determination of the cost-effectiveness of any intervention requires measures of both the cost and the effectiveness of the intervention. For an intervention to be more cost-effective than another, it either has to cost less and be at least as effective, or has to generate sufficient added value to justify the additional cost. Although a current procedural terminology code for PSF as a standalone procedure is still being used, the American Medical Association in 2012 bundled the codes for TLIF and PSF into a single posterior interbody fusion code (https://www. cms.gov/Medicare/Medicare-Fee-for-Service-Payment/ PhysicianFeeSched/PFS-Federal-Regulation-NoticesItems/CMS1253669.html). This change will reduce both the relative value and the payment rate for this new single current procedural terminology code as compared with the payment rates for the 2 previous codes used to report the procedures. However, because of the additional implant cost and the additional time required to insert an interbody device, TLIF will likely cost more.

The other half of the cost-effectiveness equation is measuring an intervention's effectiveness. Health gains or losses after an intervention are measured as qualityadjusted life years (QALYs), ${ }^{11,17}$ which take into account both the quantity and the quality of life. The QALY is the arithmetic product of life expectancy and a measure of the quality of the remaining life years. Several generic preference-weighted health state classification questionnaires, which combine a health-status measure with a societal value or utility for each health state, ${ }^{4}$ are used in economic studies. The most widely used questionnaires are the EQ-5D ${ }^{13}$ and the Short Form-6D (SF-6D). ${ }^{5,6}$ However, several studies have shown that although both the EQ-5D and SF-6D are psychometrically valid measures of health state utility in patients with low-back pain, they cannot be used interchangeably. ${ }^{22,24,25,32,33}$ Differences in the health state utility values derived from the EQ-5D and SF-6D are substantial enough that several cost-effectiveness studies present their results using both the EQ-5D and the SF-6D as part of the sensitivity analysis. ${ }^{34,35}$

The purpose of this study was to determine for patients with spondylolisthesis enrolled in the National Neurosurgery Quality and Outcomes Database $\left(\mathrm{N}^{2} \mathrm{QOD}\right)^{2,26,27}$ at what threshold of increased surgical cost TLIF will be- come cost-prohibitive relative to PSF when both EQ-5D and SF-6D health state utility values are considered.

\section{Methods}

In October 2014, the $\mathrm{N}^{2} \mathrm{QOD}$ database was queried to retrieve the records of those patients who had a diagnosis of spondylolisthesis, a 1-level or 2-level posterior lumbar fusion with or without an interbody graft, and complete baseline and 12-month follow-up data. Only patients with spondylolisthesis were included in this study, as the definition for this pathology is widely accepted, and surgical fusion is considered an effective treatment for this condition. As per the $\mathrm{N}^{2} \mathrm{QOD}$ registry inclusion criteria, only patients with vertebral slips of Meyerding ${ }^{28}$ Grade I or lower and who had not previously undergone surgery were included. Delineation between isthmic and degenerative types of spondylolisthesis was not available. Patients who had a concurrent or subsequent anterior procedure, such as an anterior lumbar interbody fusion, or a lateral access procedure, such as an extreme-lateral interbody fusion or direct lateral interbody fusion, were excluded. Patients who underwent a noninstrumented fusion or a greater than 2-level fusion were also excluded.

To control for an individual surgeon selection bias that is inherent in surgical decision making, patients who had undergone PSF were propensity matched to patients who had undergone TLIF; the patients were matched on the following variables: age, sex, body mass index, smoking status, race, educational level, employment status, presence of an anxiety disorder, insurance status, workers' compensation status, symptom duration, American Society of Anesthesiologists grade, number of levels fused, preoperative back and leg pain numeric rating scales (ranging from 0 to 10$)^{23}$ and Oswestry Disability Index (ODI) ${ }^{14,15}$ and $\mathrm{EQ}-5 \mathrm{D}^{13}$ scores. The propensity matching allows for matching multiple patient characteristics across groups without one-on-one matching of each case to a control.9,31 As none of the short forms (36-Item Short Form Health Survey [SF-36] or Short Form-12) ${ }^{37}$ are collected as part of the $\mathrm{N}^{2} \mathrm{QOD}$ registry, the SF-6D scores were estimated from the ODI scores with a previously published logistic regression model. ${ }^{7}$

Statistical analysis was carried out with IBM SPSS software version 21.0. To account for multiple concurrent analyses, statistical significance was set at the $p<0.01$ level for both the propensity-matching analysis and subsequent comparisons. Student's t-test was used to determine any statistical significance of differences between continuous demographic variables and to compare preoperative and postoperative health-related quality of life scores of the PSF group with those of the TLIF groups. The Fisher exact test was used to compare categorical variables of the 2 groups.

\section{Results}

The search of the $\mathrm{N}^{2} \mathrm{QOD}$ database identified 2035 patients who underwent lumbar fusion between the inception of the registry in March 2012 and October 2013. For 1722 of these patients (84.6\%), 12-month follow-up data were available. This cohort included 771 patients (44.8\%) with 
spondylolisthesis, of whom 134 (17.4\%) underwent PSF and $637(82.6 \%)$ TLIF. After the propensity matching, 101 cases from each group were included in the analysis.

As expected after propensity matching, the TLIF and PSF cohorts were similar in demographic, health status, and health insurance data (Table 1). Operative time and blood loss, hospital length of stay, and 30-day and 90-day readmission rates were also similar for the 2 groups (Table 2). Both TLIF and PSF improved the scores for back and leg pain, ODI, EQ-5D, and SF-6D at 3 and 12 months after surgery relative to baseline. Twelve months after sur-

TABLE 1. Summary of the demographic, health status, and health insurance data of the patients in this study*

\begin{tabular}{|c|c|c|c|}
\hline \multirow[b]{2}{*}{ Variable } & \multicolumn{2}{|c|}{ Treatment } & \multirow[b]{2}{*}{$\mathrm{p}$ Value } \\
\hline & $\begin{array}{c}\text { TLIF } \\
(n=101)\end{array}$ & $\begin{array}{c}\text { PSF } \\
(n=101)\end{array}$ & \\
\hline Mean age in yrs (SD) & $63.3(11.1)$ & $65.3(9.5)$ & 0.186 \\
\hline Male & 42 & 32 & 0.189 \\
\hline Mean BMI (SD) & $31.9(7.0)$ & $31.3(6.3)$ & 0.581 \\
\hline Smoking & & & 0.623 \\
\hline Current every-day smoker & 12 & 8 & \\
\hline Current some-days smoker & 1 & 1 & \\
\hline Former smoker & 36 & 31 & \\
\hline Never a smoker & 51 & 58 & \\
\hline Unknown & 1 & 3 & \\
\hline Race & & & 0.540 \\
\hline White & 94 & 97 & \\
\hline Native American & 1 & 0 & \\
\hline African American & 5 & 4 & \\
\hline Asian & 1 & 0 & \\
\hline Education & & & 0.244 \\
\hline$<$ High school & 5 & 8 & \\
\hline High school & 35 & 40 & \\
\hline 2-yr college & 19 & 25 & \\
\hline 4-yr college & 24 & 18 & \\
\hline Postgraduate & 18 & 10 & \\
\hline Employment status & & & 0.187 \\
\hline Employed, currently working & 32 & 25 & \\
\hline Employed, not currently working & 7 & 3 & \\
\hline Unemployed & 62 & 73 & \\
\hline Anxiety disorder & 14 & 11 & 0.670 \\
\hline Insurance status & & & 0.535 \\
\hline Uninsured & 0 & 1 & \\
\hline Medicare & 47 & 50 & \\
\hline Medicaid & 4 & 1 & \\
\hline VA/government & 2 & 3 & \\
\hline Private & 48 & 46 & \\
\hline Workers' compensation & & & 0.194 \\
\hline No & 99 & 95 & \\
\hline Yes & 2 & 3 & \\
\hline Unknown & 0 & 3 & \\
\hline
\end{tabular}

$\mathrm{BMI}=$ body mass index $; \mathrm{VA}=$ Department of Veterans Affairs.

${ }^{*}$ Data represent number of patients, unless indicated otherwise. gery, patients who had undergone TLIF had a statistically significantly greater improvement in the mean ODI score than the PSF patients (30.4 vs 21.1, $\mathrm{p}=0.001)$. The TLIF patients also had greater improvements in the mean scores for back pain (4.2 vs 3.5, $\mathrm{p}=0.090)$ and leg pain (4.6 vs $3.7, p=0.096$ ) than those in the PSF group, but these differences did not reach statistical significance. Both groups had similar gains in the EQ-5D utility scores (mean 0.25 vs $0.22, p=0.415$ ). However, gains in the SF-6D utility scores were statistically significantly greater for the TLIF group than for the PSF group (0.16 vs $0.11, p=0.001)$ (Table 3 ).

Both EQ-5D and SF-56D utility values indicated that TLIF gave greater gains in QALYs than PSF. However, according to the EQ-5D utility values, the QALY gain with TLIF relative to PSF was 0.03; in contrast, for the SF-6D utility values, the QALY gain with TLIF relative to PSF was 0.05 . Thus, at a cost-effectiveness threshold of $\$ 100,000,38$ TLIF would be cost-prohibitive at surgical costs exceeding those of PSF by more than $\$ 4830(\$ 100,000 \times 0.04830)$ according to the SF-6D-based QALYs. However, on the basis of EQ-5D-based QALYs, TLIF would become costprohibitive when its surgical costs exceeded those of PSF by $\$ 2960(\$ 100,000 \times 0.0296)$. When we used the 2014 US per capita gross domestic product of $\$ 53,042$ (from http://data.worldbank.org/indicator/NY.GDP.PCAP.CD) as a more stringent cost-effectiveness threshold, ${ }^{39}$ TLIF became cost-prohibitive at surgical costs exceeding those of PSF by $\$ 2562(\$ 53,042 \times 0.0483)$ according to the SF$6 \mathrm{D}-$ based QALYs or at a surgical costs greater exceeding those of PSF by $\$ 1570(\$ 53,042 \times 0.0296)$ according to the EQ-5D-derived QALYs.

TABLE 2. Summary of surgical and discharge data*

\begin{tabular}{|c|c|c|c|}
\hline \multirow[b]{2}{*}{ Variable } & \multicolumn{2}{|c|}{ Treatment (SD) } & \multirow[b]{2}{*}{ p Value } \\
\hline & TLIF & PSF & \\
\hline ASA grade & & & 0.106 \\
\hline 1 & 1 & 3 & \\
\hline 2 & 51 & 37 & \\
\hline 3 & 49 & 58 & \\
\hline 4 & 0 & 3 & \\
\hline No. of levels & & & 0.132 \\
\hline 1 & 74 & 63 & \\
\hline 2 & 27 & 38 & \\
\hline Mean EBL in ml & $381.5(361.8)$ & $418.7(295.1)$ & 0.484 \\
\hline Mean op time in mins & $199.0(91.2)$ & $194.2(93.0)$ & 0.711 \\
\hline LOS in days & $3.74(2.3)$ & $4.0(7.6)$ & 0.646 \\
\hline Discharge disposition & & & 0.955 \\
\hline Home routine & 71 & 68 & \\
\hline Home w/ health service & 11 & 11 & \\
\hline Postacute care setting & 16 & 18 & \\
\hline Transfer to acute care & 3 & 4 & \\
\hline \multicolumn{4}{|l|}{ Readmission } \\
\hline w/in 30 days & 0 & 2 & 0.498 \\
\hline w/in 3 mos & 1 & 4 & 0.369 \\
\hline
\end{tabular}

ASA = American Society of Anesthesiologists; EBL = estimated blood loss; LOS = length of stay.

* Data represent number of patients, unless indicated otherwise. 
TABLE 3. Summary of surgical outcomes data*

\begin{tabular}{cccc}
\hline & \multicolumn{2}{c}{ Treatment } & \\
\cline { 2 - 3 } Score & TLIF & PSF & p Value \\
\hline Back pain & & & \\
\hline Baseline & $7.1(2.2)$ & $7.3(2.4)$ & 0.444 \\
\hline 3 mos & $4.3(2.9)$ & $3.9(3.0)$ & 0.332 \\
\hline 12 mos & $4.2(3.1)$ & $3.5(3.2)$ & 0.090 \\
\hline Leg pain & & & \\
\hline Baseline & $6.8(3.1)$ & $6.8(3.0)$ & 1.000 \\
\hline 3 mos & $4.9(3.9)$ & $4.4(4.1)$ & 0.426 \\
\hline 12 mos & $4.6(3.9)$ & $3.7(3.8)$ & 0.096 \\
\hline ODI & & & \\
\hline Baseline & $53.6(15.8)$ & $52.7(17.4)$ & 0.685 \\
\hline 3 mos & $25.3(16.8)$ & $19.8(19.0)$ & 0.034 \\
\hline 12 mos & $30.4(18.6)$ & $21.1(19.2)$ & 0.001 \\
\hline EQ-5D & & & \\
\hline Baseline & $0.51(0.22)$ & $0.51(0.22)$ & 0.976 \\
\hline 3 mos & $0.24(0.25)$ & $0.25(0.29)$ & 0.760 \\
\hline 12 mos & $0.25(0.26)$ & $0.22(0.25)$ & 0.415 \\
\hline SF-6D & & & \\
\hline Baseline & $0.51(0.08)$ & $0.51(0.09)$ & 0.685 \\
\hline 3 mos & $0.13(0.09)$ & $0.10(0.10)$ & 0.034 \\
\hline 12 mos & $0.16(0.10)$ & $0.11(0.10)$ & 0.001 \\
\hline * Data represent mean scores (SD). & &
\end{tabular}

* Data represent mean scores (SD).

\section{Discussion}

The $\mathrm{N}^{2} \mathrm{QOD}$ is prospective multicenter, multisurgeon quality assurance program with a substantial infrastructure to optimize data integrity and validity.,26,27 Although patient enrollment is based on widely accepted, welldefined etiologic diagnostic criteria, surgical treatment is determined by the standard practice of the individual surgeon. The use of a large registry allows researchers to pragmatically evaluate surgical interventions for a specific diagnostic indication.

Reflective of the increasing use of interbody support with posterior fusions, ${ }^{29}$ most spondylolisthesis patients in the current study (83\%) underwent TLIF, and only $17 \%$ PSF. This trend in use of these 2 treatments has been widely observed despite the lack of strong evidence supporting the routine use of TLIF.

Although previous studies ${ }^{1,16,20}$ have shown that TLIF results in longer operative times and greater estimated blood loss than PSF, the current study showed no difference in these surgical parameters between the 2 treatment groups. This lack of a difference may be due to increased surgical proficiency, improvement in surgical techniques and tools, inclusion of only 1-level and 2-level fusions in the present study, and variability in surgical skill. Previous studies have also reported higher complication rates with TLIF, ${ }^{19,21,30}$ but these were not observed in the current study. In addition, the length of stay, discharge disposition, and 30-day and 90-day readmission rates were also similar for the 2 groups. The observed similarities in perioperative parameters and complication and readmission rates suggested no substantial difference in direct costs between the 2 treatments, except for the interbody implant and graft material.

Patients in the TLIF group had substantially better ODI scores at 3 and 12 months after surgery than those in the PSF group. However, the TLIF and PSF groups had similar improvements in back and leg pain scores. These inconsistencies may be explained by the unidimensional property of the pain scores, which may limit their sensitivity to change, in contrast to the ODI score, which is multidimensional.

Greater health utility gains were observed in the TLIF group than in the PSF group, but these gains were greater when the SF-6D rather than the EQ-5D questionnaire was used. The EQ-5D score is less sensitive to change than that of the SF-6D for patients with low-back disorders. ${ }^{22,24,25 \text {, }}$ 32,33 These differences in health utility valuation for the same disease entity in the same cohort have prompted researchers to present the results of cost-effectiveness analyses for both valuation methods. Several studies have shown that whereas the SF-6D and ODI scores are dispersed and normally distributed, the EQ-5D scores tend to cluster and to have a bimodal distribution. ${ }^{6,33}$ The EQ-5D score has also been shown to have a ceiling effect in patients with low-back pain. ${ }^{6,24,25,33}$ In addition, the EQ-5D currently in wide use has 3 choices for each domain and may therefore not be sensitive enough to detect small changes in health status.

Depending on which cost-effectiveness threshold and health utility value were used, the increased surgical cost at which TLIF becomes less cost-effective than PSF varied from $\$ 1570$ to $\$ 4830$. The use of more expensive bone graft substitutes or enhancers in PSF or TLIF can change this cost-per-QALY ratio. However, the $\mathrm{N}^{2} \mathrm{QOD}$ registry does not have sufficient granularity to allow analysis of this issue.

There are limitations to this study, some of which are inherent to the use of registry data. Isthmic and degenerative spondylolisthesis types were not delineated in the present study. Information about the proportion of TLIF patients in our cohort who underwent a minimally invasive approach was also not available. The relatively small sample size in the present study may have caused a failure to detect statistically significant differences, especially in the ordinal values of back and leg pain scores. The relatively short length of follow-up precluded any study on the relative durability of TLIF and PSF. Although the SF-6D should ideally be derived from either the Short Form-12 or the SF-36, 4,5 neither of these 2 forms was administered as part of the $\mathrm{N}^{2} \mathrm{QOD}$. Thus, the SF-6D transformed from the ODI was used. ${ }^{7}$ Of note, previous studies have shown no statistically significant difference between the SF-6D score estimated from the ODI and the SF-36-derived SF6D score in a cohort of patients who underwent lumbar fusion surgery for degenerative conditions. ${ }^{\text {? }}$

\section{Conclusions}

Using a large national spine registry, we showed here that operative time, length of hospital stay, complication rates, discharge disposition, and readmission rates were similar for both TLIF and PSF. QALY gains with TLIF 
calculated with the SF-6D were greater than those calculated with EQ-5D, and these gains may justify the additional costs associated with TLIF compared with PSF. Importantly, this study demonstrates that the cost per QALY depends on the measure of health utility selected, durability of the intervention, readmission rates, and the accuracy of the cost assumptions.

\section{References}

1. Abdu WA, Lurie JD, Spratt KF, Tosteson ANA, Zhao W, Tosteson TD, et al: Degenerative spondylolisthesis: does fusion method influence outcome? Four-year results of the spine patient outcomes research trial. Spine (Phila Pa 1976) 34:2351-2360, 2009

2. Asher AL, Speroff T, Dittus RS, Parker SL, Davies JM, Selden N, et al: The National Neurosurgery Quality and Outcomes Database ( $\left.{ }^{2} \mathrm{QOD}\right)$ : a collaborative North American outcomes registry to advance value-based spine care. Spine (Phila Pa 1976) 39 (22 Suppl 1):S106-S116, 2014

3. Audat Z, Moutasem O, Yousef K, Mohammad B: Comparison of clinical and radiological results of posterolateral fusion, posterior lumbar interbody fusion and transforaminal lumbar interbody fusion techniques in the treatment of degenerative lumbar spine. Singapore Med J 53:183-187, 2012

4. Brazier J, Deverill M, Green C: A review of the use of health status measures in economic evaluation. J Health Serv Res Policy 4:174-184, 1999

5. Brazier J, Roberts J, Deverill M: The estimation of a preference-based measure of health from the SF-36. J Health Econ 21:271-292, 2002

6. Brazier J, Roberts J, Tsuchiya A, Busschbach J: A comparison of the EQ-5D and SF-6D across seven patient groups. Health Econ 13:873-884, 2004

7. Carreon LY, Glassman SD, McDonough CM, Rampersaud R, Berven S, Shainline M: Predicting SF-6D utility scores from the Oswestry disability index and numeric rating scales for back and leg pain. Spine (Phila Pa 1976) 34:2085-2089, 2009

8. Christensen A, Høy K, Bünger C, Helmig P, Hansen ES, Andersen $\mathrm{T}$, et al: Transforaminal lumbar interbody fusion vs. posterolateral instrumented fusion: cost-utility evaluation along side an RCT with a 2-year follow-up. Eur Spine J 23:1137-1143, 2014

9. D’Agostino RB Jr: Propensity score methods for bias reduction in the comparison of a treatment to a non-randomized control group. Stat Med 17:2265-2281, 1998

10. Dehoux E, Fourati E, Madi K, Reddy B, Segal P: Posterolateral versus interbody fusion in isthmic spondylolisthesis: functional results in 52 cases with a minimum follow-up of 6 years. Acta Orthop Belg 70:578-582, 2004

11. Drummond MF, Sculpher MJ, Torrance GW, O'Brien BJ, Stoddart GL: Methods for the Economic Evaluation of Health Care Programmes. New York: Oxford University Press, 2005

12. Ekman P, Möller H, Tullberg T, Neumann P, Hedlund R: Posterior lumbar interbody fusion versus posterolateral fusion in adult isthmic spondylolisthesis. Spine (Phila Pa 1976) 32:2178-2183, 2007

13. EuroQol Group: EuroQol-a new facility for the measurement of health-related quality of life. Health Policy 16:199208, 1990

14. Fairbank JC, Couper J, Davies JB, O'Brien JP: The Oswestry low back pain disability questionnaire. Physiotherapy 66:271-273, 1980

15. Fairbank JC, Pynsent PB: The Oswestry Disability Index. Spine (Phila Pa 1976) 25:2940-2952, 2000

16. Farrokhi MR, Rahmanian A, Masoudi MS: Posterolateral versus posterior interbody fusion in isthmic spondylolisthesis. J Neurotrauma 29:1567-1573, 2012

17. Gold MR, Siegel JE, Russel LB, Weinstein MC: Cost-Effectiveness in Health and Medicine. Oxford: Oxford University Press, 1996

18. Ha KY, Na KH, Shin JH, Kim KW: Comparison of posterolateral fusion with and without additional posterior lumbar interbody fusion for degenerative lumbar spondylolisthesis. J Spinal Disord Tech 21:229-234, 2008

19. Hee HT, Castro FP Jr, Majd ME, Holt RT, Myers L: Anterior/ posterior lumbar fusion versus transforaminal lumbar interbody fusion: analysis of complications and predictive factors. J Spinal Disord 14:533-540, 2001

20. Høy K, Bünger C, Niederman B, Helmig P, Hansen ES, Li HS, et al: Transforaminal lumbar interbody fusion (TLIF) versus posterior instrumented fusion (PLF) in degenerative lumbar disorders: A randomized clinical trial with 2-year follow-up. Eur Spine J 22:2022-2029, 2013

21. Humphreys SC, Hodges SD, Patwardhan AG, Eck JC, Murphy RB, Covington LA: Comparison of posterior and transforaminal approaches to lumbar interbody fusion. Spine (Phila Pa 1976) 26:567-571, 2001

22. Kind P, Dolan P, Gudex C, Williams A: Variations in population health status: results from a United Kingdom national questionnaire survey. BMJ 316:736-741, 1998

23. McCaffery M, Beebe A: Pain: A Clinical Manual for Nursing Practice. Baltimore: Mosby, 1993

24. McDonough CM, Grove MR, Tosteson TD, Lurie JD, Hilibrand AS, Tosteson AN: Comparison of EQ-5D, HUI, and SF-36-derived societal health state values among spine patient outcomes research trial (SPORT) participants. Qual Life Res 14:1321-1332, 2005

25. McDonough CM, Tosteson TD, Tosteson AN, Jette AM, Grove MR, Weinstein JN: A longitudinal comparison of 5 preference-weighted health state classification systems in persons with intervertebral disk herniation. Med Decis Making 31:270-280, 2011

26. McGirt MJ, Parker SL, Asher AL, Norvell D, Sherry N, Devin CJ: Role of prospective registries in defining the value and effectiveness of spine care. Spine (Phila Pa 1976) 39 (22 Suppl 1):S117-S128, 2014

27. McGirt MJ, Speroff T, Dittus RS, Harrell FE Jr, Asher AL: The National Neurosurgery Quality and Outcomes Database $\left(\mathrm{N}^{2} \mathrm{QOD}\right)$ : general overview and pilot-year project description. Neurosurg Focus 34(1):E6, 2013

28. Meyerding HW: Spondylolisthesis. Surg Gynecol Obstet 54:371-377, 1931

29. Pannell WC, Savin DD, Scott TP, Wang JC, Daubs MD: Trends in the surgical treatment of lumbar spine disease in the United States. Spine J 15:1719-1727, 2015

30. Potter BK, Freedman BA, Verwiebe EG, Hall JM, Polly DW Jr, Kuklo TR: Transforaminal lumbar interbody fusion: clinical and radiographic results and complications in 100 consecutive patients. J Spinal Disord Tech 18:337-346, 2005

31. Rosenbaum PR: Model-based direct adjustment. J Am Stat Assoc 82:387-394, 1987

32. Sach TH, Barton GR, Jenkinson C, Doherty M, Avery AJ, Muir KR: Comparing cost-utility estimates: does the choice of EQ-5D or SF-6D matter? Med Care 47:889-894, 2009

33. Søgaard R, Christensen FB, Videbaek TS, Bünger C, Christiansen T: Interchangeability of the EQ-5D and the SF-6D in long-lasting low back pain. Value Health 12:606-612, 2009

34. Tosteson AN, Lurie JD, Tosteson TD, Skinner JS, Herkowitz $\mathrm{H}$, Albert T, et al: Surgical treatment of spinal stenosis with and without degenerative spondylolisthesis: cost-effectiveness after 2 years. Ann Intern Med 149:845-853, 2008

35. Tosteson AN, Skinner JS, Tosteson TD, Lurie JD, Andersson GB, Berven S, et al: The cost effectiveness of surgical versus nonoperative treatment for lumbar disc herniation over two 
years: evidence from the Spine Patient Outcomes Research Trial (SPORT). Spine (Phila Pa 1976) 33:2108-2115, 2008

36. Wang YP, Fei Q, Qiu GX, Zhao H, Zhang JG, Tian Y, et al: Outcome of posterolateral fusion versus circumferential fusion with cage for lumbar stenosis and low degree lumbar spondylolisthesis. Chin Med Sci J 21:41-47, 2006

37. Ware JE Jr, Sherbourne CD: The MOS 36-Item Short Form Health Survey (SF-36). I. Conceptual framework and item selection. Med Care 30:473-483, 1992

38. Winkelmayer WC, Weinstein MC, Mittleman MA, Glynn RJ, Pliskin JS: Health economic evaluations: the special case of end-stage renal disease treatment. Med Decis Making 22:417-430, 2002

39. World Health Organization: Macroeconomics and Health: Investing in Health for Economic Development: Report of the Commission on Macroeconomics and Health. Geneva: World Health Organization, 2001

40. Zhou ZJ, Zhao FD, Fang XQ, Zhao X, Fan SW: Meta-analysis of instrumented posterior interbody fusion versus instrumented posterolateral fusion in the lumbar spine. J Neurosurg Spine 15:295-310, 2011

\section{Disclosures}

Dr. Glassman is employed by Norton Healthcare, holds patents with Medtronic, has received clinical or research support not related to this study from Norton Healthcare, and has received royalties from Medtronic. Dr. Carreon is employed by Norton
Healthcare; has received clinical or research support not related to this study from Norton Healthcare, AO Spine, OREF, and SRS; has received travel funds from OREF, DOD, the Association for Collaborative Spine Research, Center for Spine Surgery and Research of the University of Southern Denmark, and the University of Louisville Institutional Review Board; and has received honoraria for participation in review panels at the National Institutes of Health, Children's Tumor Foundation, and the Global Evidence Advisory Board, Medtronic. Dr. Mummaneni is a consultant for DePuy Spine, has direct stock ownership in Spinicity/ ISD, and receives royalties from DePuy Spine and from the publishers Taylor and Francis, Thieme, and Springer.

\section{Author Contributions}

Conception and design: Carreon, Glassman. Acquisition of data: all authors. Analysis and interpretation of data: Carreon. Drafting the article: Carreon. Critically revising the article: Carreon, Glassman, Ghogawala, Mummaneni. Reviewed submitted version of manuscript: Carreon, Glassman, Ghogawala, Mummaneni. Approved the final version of the manuscript on behalf of all authors: Carreon. Statistical analysis: Carreon. Administrative/ technical/material support: McGirt, Asher.

\section{Correspondence}

Leah Y. Carreon, Norton Leatherman Spine Center, 210 E. Gray St., Ste. 900, Louisville, KY 40202. email: leah.carreon@ nortonhealthcare.org. 